\title{
Reasons for the Failure of Technology Incubator - Failure Mechanism and Empirical Study of Technology Incubation Platform Under the Background of Big Data
}

\author{
Lv Bo, Zhi Yechao*, Gu Qiaoling \\ Business School, Beijing Wuzi University, Beijing, China \\ Email address: \\ 1vbo73@sina.com (Lv Bo), zyc201408@sina.com (Zhi Yechao), gupanpan0131@sina.com (Gu Qiaoling) \\ ${ }^{*}$ Corresponding author
}

To cite this article:

Lv Bo, Zhi Yechao, Gu Qiaoling. Reasons for the Failure of Technology Incubator - Failure Mechanism and Empirical Study of Technology Incubation Platform Under the Background of Big Data. American Journal of Management Science and Engineering.

Vol. 4, No. 4, 2019, pp. 66-75. doi: 10.11648/j.ajmse.20190404.12

Received: October 11, 2019; Accepted: November 1, 2019; Published: November 8, 2019

\begin{abstract}
In recent years, the technology incubation platform is facing a new ecological environment. The background of big data brought by cloud computing and big data has increased the random disturbance effect on technology incubation platform. The failure of some technology incubation platforms has caused academic controversies. This paper conducts theoretical research and empirical test for these academic controversies, and the empirical conclusions of this paper provide a more comprehensive and reasonable explanation for current academic controversies. In order to describe the failure phenomena of technology incubation platform, this paper innovatively proposes the concept of failure effects and failure coefficients, constructs failure effects model and deduces the failure mechanism formula by using the principle of Stochastic Frontier Analysis (SFA). On the basis of literature research, combined with the background characteristics of the big data, 4 dependent variables and 14 random influence variables were selected, and the Chinese technology incubator platform was taken as an example to empirically analyze failure effects model. The paper finds that the independent variables can be divided into three categories: positive, negative and partially irrelevant. When corresponding to negatively correlate variables or unrelated variables, dependent variables will show the failure phenomenon, that is, partial failure of technology incubation platform.
\end{abstract}

Keywords: Failure Effects, The Background of Big Data, Technology Incubation Platform, Stochastic Frontier Analysis (SFA), Mechanisms

\section{Introduction}

The innovation-oriented technology incubation platform is a worldwide phenomenon, technology incubation platform is a platform to provide business support and technology transfer plans for start-ups, traditional platforms include business incubators, university incubators, etc., they all are innovation-oriented, provide knowledge environment and business opportunities for start-ups, and promote interactive and high-speed growth of start-ups. [1] In recent years, cloud computing and big data have brought about a new technological revolution, under the background of the big data, a large number of start-ups cultivated by the technology incubator platform are no longer traditional industries, but mainly with knowledge, network, virtual and new formats, and gave birth to a new technology incubation platform -- maker space. The technology incubation platform is facing a new ecological environment, and the random impact variables increase, which poses a challenge to the traditional mechanism. Therefore, this paper takes Chinese technology incubation platform as an example to study the failure effects of random variables under the background of big data, which is of great significance to improve the performance of Chinese technology incubation platform and promote the success of new-type enterprises.

As the main carrier of cultivating start-ups, Chinese technology incubation platform has experienced a cycle of birth and development after more than 30 years of development since 1987. Dylan Sutherland (2005) predicted the development of business incubators in China when examining Chinese science parks and the small number of 
business incubators at that time. He believed that business incubators were a vibrant workplace and would develop rapidly in quantity and scale in the future. And he suggested that foreign companies should consider whether to enter science parks or business incubators before investing in China [2] According to China torch statistical yearbook in 2017, from the first business incubator in 1987, there were 614 in 2007 and more than 3,200 in 2017. After the new technological revolution background was formally put forward in 2015, this pattern was accelerated and optimized, and a new situation based on the development of the big data background was rapidly formed. In 2018, Chinese technology incubation platform includes more than 3,200 business incubators, more than 5,000 maker spaces and many university incubators. While the technology incubation platform is rapidly developing, it also faces the survival of the fittest, and individual platforms were invalid, such as closed or failed. For example, Shenzhen maker space "Peacock Institute", "basement", and Beijing maker space "Mad Space" have closed. "Science and Technology Daily" once reported in an interview with "Is Chinese Incubator Really Crazy", and the Ministry of Science and Technology responded that "partial truth is not equal to the overall reality".

The impact of the Internet and mobile Internet has brought about an increase in random variables, accelerated the development and differentiation of technology incubation platforms, and caused many failure phenomena. In fact, this kind of failure phenomenon has existed for a long time, and has already attracted the attention of the academia. However, the background of new technological revolution has intensified this kind of failure phenomenon. Harwit (2002) earlier focused on the failure effects of Chinese start-ups after being invested, and mentioned this fact in his paper: In early 2000, the China Internet Incubation Center (CIIC) in Shanghai claimed that an Internet auction site (Auctiondown.com) had received $\$ 500,000$ from a US venture capital firm, but the company has not been in operation for more than a year. [3] In the background of the new technological revolution, the failure effects of new start-ups is also common in the technology incubator platform, for example, the long-circulated "death list of Chinese Internet companies" involves more than 1,000 enterprises in 16 fields. As a breeding carrier for start-ups, the effectiveness of technology incubation platform will be questioned if a large number of start-ups fall into operational difficulties or fail.

The failure of technology incubation platform has been studied for a long time. Sang Suk Lee (2004) took the 14 key success factors of the business incubator as the research object empirical research found that 13 of the key success factors were not statistically significant, only "the clarity of objectives and operational strategies" has passed significant verification, and the article believes that this only effective indicator has only a significant effect on American university incubator managers, and is not statistically significant for Korean university incubators, so he analyzed that this may be associated with unstable business incubation in Korea. Although South Korea has set up a large number of technology incubation platforms to promote the creation of small enterprises, most of them are unknown, and South Korea lacks management experience in technology incubation system. Christine Tamasy (2007) based his empirical research to suggest that technology incubators cannot support entrepreneurship, innovation and regional development, fail to fulfill their intended role as a policy tool, and suggest that technology-based business incubators should be operated by private collectives with non-public funds. [4] A study by Elisa Salvador (2011) on business divisions shows that there is no decisive difference between business divisions located in technology parks or business incubators and those located outside, except that the former tends to maintain continuous contact with headquarters. [5] Luana Pontes Tondolo and BEL (2016) conducted a study on whether business incubators bring benefits to entrepreneurs, universities and local communities. They believe that due to the small number of successful business incubators, the contribution of incubators to work, income and tax are very small; for universities, there is no direct benefit; as for the impact of entrepreneurs, many services are not properly provided, especially for those who need financial capital services; although investment in incubators costs a lot of money, technology incubators provide the benefits of the region are limited. [6]

Some scholars have discussed the causes of failure phenomenon. This paper believes that there are three main representative views: First, it does not conform to the regional positioning. A typical example is the "specialization" of regional innovation proposed by the scholar Evert Jan Davelaar (1988), that is, the central (metropolitan) region is in a favorable position in terms of high-quality product innovation, while more peripheral regions focus on process innovation. If Incubating companies that do not comply with regional positioning can easily lead to failure. [7] Second, sponsor preference. N Dutt (2015) believed that the sponsors of the technology incubator will lead to system errors, and the sponsorship of technology incubators by private, government, academic and nongovernmental organizations will affect the types of services provided. Private sponsorship tends to support start-ups in the market development phase and emphasizes the provision of financial services; academic organizations emphasize advisory services; nongovernmental organizations emphasize training; and government support start-ups at a lower stage of market development and emphasize the provision of a wide range of services. If the enterprise is not suitable for an incubator, the incubation effect will be affected. [8] Third, performance management problems. Skeptics generally believe that the failure is due to the performance management of the technology incubation platform. As Sang Suk Lee (2004) put forward, the government should be aware of the performance difference of technology incubation platform, and provide selective support.

In this paper, the above failure phenomenon is called the failure effects of the technology incubation platform, which means that the input of the technology incubation platform does not achieve the expected output effect, that is, the 
incubation effect is very poor. Corresponding to the failure effects, the effective effect refers to the obvious effects of the investment of the technology incubation platform. The most direct evidence of the failure effects in practice is the long list of a large number of new business failures that are spread on the Internet each year. For the academic controversy caused by the failure of technology incubation platform, this paper will conduct theoretical research and empirical test.

\section{Failure Mechanism Formula Construction and Variable Design}

This paper adopts the following design ideas: first, construct the model; then carry out mechanism analysis and variable definition; complete data correlation analysis and reliability test based on data collection; apply model to empirical analysis by software; finally draw empirical conclusion and analyze.

\subsection{Construct Failure Effects Model}

The fundamental reason why Technology Incubation Platform promotes the development of start-ups lies in the interaction between Technology Incubation Platform and start-ups, which generates innovation driving force to promote innovation process. As for the research on the technology incubation platform effects, literature research found that there are three main types of quantitative research models: index method, data envelopment analysis (DEA) and stochastic frontier analysis (SFA). [9] The index method requires sufficient price data, which is a non-parametric method and is not suitable for random analysis in complex new environments (such as the background of big data). DEA is often used in a stable environment, both Zhang Jiao and Yin Qun (2010), and Wang Jing and Wang Keyi (2012) have proposed different indicators, but under the disturbance of a large number of random variables in the background of big data, the results unstable and not applicable. Only the SFA can not only reflect the statistical characteristics of the random samples collected in the background of the new technological revolution, but also help to reveal the law. Therefore, this paper uses the SFA to build the model. The theory of stochastic process was first established by Kolmogorov (1931) and Dube (1953). Farrell (1957) put forward the concept of frontier production function when he studied the problem of production efficiency. Later, Aigner (1977) and Van den Broeck (1977) independently proposed SFA. Later, different scholars used this method to conduct extensive empirical research on the influencing factors in different fields. In the field of technology incubation platform, Mark (2002) first proposed that the performance of Technology Incubation Platform is related to the investment factors of Technology Incubation Platform and the investment factors of start-ups. [10] Based on the research of Mark et al., the paper deduces the formula for the failure effects mechanism of the technology incubation platform as follows:

In this paper, "Y" is used to express failure effects, and it is defined as dependent variable. Input factors of science and technology incubation platform and start-ups are both taken as independent variables, respectively expressed by " $X$ " and " $Z$ ", and formula (1) can be obtained:

$$
Y=\alpha X^{\beta} Z^{\gamma}
$$

In the formula, $\alpha$ is called the cooperation factor, depending on the cooperation time, matching degree, intensity, cooperation depth and cooperation breadth of the technology incubation platform and the start-ups. $\beta$ and $\gamma$ are respectively the investment index of technology incubation platform and the investment index of start-ups, they are elastic values, depending on the willingness, attention and awareness of cooperation between the two parties. Willingness refers to the willingness of both parties to cooperate; attention refers to whether the two sides pay attention to the problems existing in the cooperation and whether to take immediate action; awareness refers to the awareness of knowledge sharing, resource sharing and information sharing between two parties.

Find the partial derivative of " $\mathrm{X}$ " and " $\mathrm{Z}$ " from equation (1), and get the formula (2).

$$
\frac{\partial Y}{\partial X \partial Z}=\alpha \beta \gamma X^{\beta-1} Y^{\gamma-1}
$$

When $\beta>1, \gamma>1$, the effect of " $X$ " and " $Z$ " on " $Y$ " is positive. And the larger the value of $\beta, \gamma$, the greater the positive effect of " $\mathrm{X}$ " and " $\mathrm{Z}$ " on " $Y$ ". According to formula (2), the reason why the technology incubation platform has an effective effect on the incubated start-ups is that $\alpha>0, \beta>$ $1, \gamma>1$. If $\alpha<0, \beta<1, \gamma<1$, there is a failure effect. The explanation of its mechanism is shown in Table 1 .

\begin{tabular}{|c|c|c|}
\hline Factor or index & Failure Effects & Effective Effects \\
\hline (l) & $\begin{array}{l}\alpha<0, \text { the technology incubation platform does not match } \\
\text { the cooperation between the start-up enterprises (hereinafter } \\
\text { referred to as two sides), and does not reflect the scale } \\
\text { advantage and cooperation effects. }\end{array}$ & $\begin{array}{l}\alpha>0 \text {, the cooperation between the two sides is matched, reflects } \\
\text { strong cooperation intensity, breadth and depth, and produces } \\
\text { obvious scale advantages and cooperation effects. }\end{array}$ \\
\hline B & $\begin{array}{l}\beta<1 \text {, the technology incubation platform turns a blind eye } \\
\text { to the problems in the cooperation, has no communication or } \\
\text { can't solve it, and cannot realize knowledge sharing, resource } \\
\text { sharing, and information sharing. }\end{array}$ & $\begin{array}{l}\beta>1 \text {, two sides have a strong willingness to cooperate, attach great } \\
\text { importance to the problems in the cooperation, communicate well } \\
\text { and solve them in a timely manner. The two sides have fully realized } \\
\text { knowledge sharing, resource sharing and information sharing. }\end{array}$ \\
\hline$\Gamma$ & $\begin{array}{l}\gamma<1 \text {, input effect of start-ups is not good, and cooperation } \\
\text { between the two sides is not matched.。 }\end{array}$ & $\begin{array}{l}\gamma>1 \text {, the investment effect of start-ups is obvious, and the two } \\
\text { sides match. }\end{array}$ \\
\hline$\alpha \beta \gamma$ (Mixing effect) & $\begin{array}{l}\alpha \beta \gamma<1 \text {, the interaction of } \alpha, \beta \text { and } \gamma \text { does not produce a } \\
\text { mixed effect. }\end{array}$ & $\alpha \beta \gamma>1$, the interaction of $\alpha, \beta$ and $\gamma$ produces a mixed effect. \\
\hline
\end{tabular}

Table 1. Comparison of Failure Effects and Effective Effects. 
According to the viewpoint of Aigner (1977), in order to describe the system failure and stochastic phenomena, a double error term is added to the equation to better estimate the maximum likelihood. Among them, $u_{i}$ measures the system efficiency loss term, which represents the failure effects in this paper; $v_{i}$ represents the random factor and measures the random error term. [11]

Substitute $\mathrm{X}_{\mathrm{i}}$ and $\mathrm{Z}_{\mathrm{i}}$ as independent variables into $Y=$ $\alpha X^{\beta} Z^{\gamma}$, then take $\ln$ values on both sides, and add $\mathrm{u}_{\mathrm{i}}$ and $\mathrm{v}_{\mathrm{i}}$, the failure effects model can be derived as:

$$
\ln Y_{i}=\ln \alpha+\beta_{\mathrm{i}} \ln X_{i}+\gamma_{\mathrm{i}} \ln Z_{i}-\mathrm{u}_{\mathrm{i}}+\mathrm{v}_{\mathrm{i}}
$$

It can be known from formula (3) that $\ln Y_{i}$ is inversely relate to $u_{i}$, and $u_{i}$ is called the failure effects value. When $u_{i}$ is the largest, the failure effect is the largest and the system output is the smallest; when $u_{i}$ is the smallest, the failure effect is the smallest and the system output is the largest.

Let the loss rate caused by the failure effects be $\theta$, then the formula is:

$$
\begin{aligned}
\theta=1- & \frac{\text { ObservedY }}{\text { FrontierY }}=1-\frac{Y_{i}}{\exp \left(\ln \alpha+\beta_{\mathrm{i}} \ln \mathrm{X}_{\mathrm{i}}+\gamma_{\mathrm{i}} \ln Z_{\mathrm{i}}+\mathrm{v}_{\mathrm{i}}\right)} \\
& =1-\frac{\exp \left(\ln \alpha+\beta_{\mathrm{i}} \ln X_{i}+\gamma_{\mathrm{i}} \ln Z_{i}-\mathrm{u}_{\mathrm{i}}+\mathrm{v}_{\mathrm{i}}\right)}{\exp \left(\ln \alpha+\beta_{\mathrm{i}} \ln X_{i}+\gamma_{\mathrm{i}} \ln Z_{i}+\mathrm{v}_{\mathrm{i}}\right)} \\
& =1-\exp \left(-\mathrm{u}_{\mathrm{i}}\right)
\end{aligned}
$$

Since FrontierY is the ideal state, the actual value ObservedY $<$ FrontierY, that is $\frac{\text { ObservedY }}{\text { FrontierY }} \in(0,1)$, the value range of the actual rate caused by the failure effects can be obtained:

$$
\theta=1-\frac{\text { ObservedY }}{\text { FrontierY }}=1-\exp \left(-\mathrm{u}_{\mathrm{i}}\right) \in(1,0)
$$

According to formula (5), the larger the $u_{i}$ value representing the failure effects, the larger the loss rate of the technology incubation platform will be, and the more inefficient the technology incubation platform will be. In the most ideal state, $u_{i}=0$, then the system loss rate of the technology incubation platform is the smallest, and the failure effect is the smallest.

In order to compare the magnitude of the failure effects $u_{i}$ and the random error $v_{i}$, the failure effects coefficient is introduced as $\lambda$ :

$$
\lambda=\frac{\delta_{\mathrm{u} 1}}{\delta_{\mathrm{v} 1}}
$$

When the value of $\lambda$ is small, it indicates that the random error $v_{i}$ is large, and the random error term becomes the main influence variable. When the value of $\lambda$ is large, the failure effects value $u_{i}$ is large, and the failure effects are obvious.

\subsection{Design of Failure Effects Variables}

The background of the big data brings about network interaction, which makes the variables of the technology incubation platform appear random and accidental. Therefore, it is necessary to use the theory of randomness to study the underlying inevitability law through the surface contingency, and analyze the random failure effects brought by the background of the big data. In order to set the variables of the failure effects, the following related literature is worth learning: First, the related research of independent variables. Domestic and foreign scholars provide a richer research perspective. Smilor (1987) studied the key success factors for effective management of the incubator system and he believed that the following elements should be included: business expertise, access to finance and capitalization, physical and financial support, community support, entrepreneurship networks, education, sense of accomplishment, tenant selection, integration with universities, and clear policies and procedures. [12] Park (1999) and others believed that an effective comprehensive business incubator should have the following elements: unified operation center; comprehensive support center, which uses computer networks to collect and distribute information for start-ups; cultural atmosphere and business classification; effective fundraising and management network system. [13] Lee (1999) and others studied University incubators and found that the key factors include: clear objectives and strategies; effective management policies; convenient infrastructure; good incubation services, human resources services, and internal and external network services. [14] Hansen (2000) and others proposed that business incubators with good performance should have the characteristics of "network", the resident enterprises should have priority access to the network, they should be good at fostering entrepreneurship, provide top-level services, create favorable interest rates and conditions for start-ups, and make start-ups enjoy economies of scale. [15] Pace (2002) believed that the start-ups' business is extremely unstable, they face high risks of failure in the first year, this situation makes the reputation of the start-ups extremely low, and it's market position needs time to be recognized by the market. The responsibility of the platform is to create conditions to help these start-ups get through the storm. [16] Shane (2002) suggested that the distance between technology incubators and university laboratories and research centers is a key factor when researching biopharmaceutical start-ups because these start-ups can't afford expensive equipment, and if they are close to the university, they can enjoy university innovations and experiments with university resources and laboratories. Colombo (2002), Link (2007) and others proposed that technology incubators should create network opportunities and provide technical network services for start-ups. [17, 18] Schwartz (2009) believed that technology incubation platform should provide effective solutions, create a favorable network of associations, establish stable financing channels, and play a key role in the first year survival of start-ups. [19] Elisa Salvador (2011) found that technology incubators can help start-ups narrow the gap between management and business, and solve the problem of funding sources. All of the above studies were conducted from external random variables. Of course, some scholars have turned their research perspectives on entrepreneurial factors. For example, Mian (1994) studied 
the essential characteristics of successful entrepreneurs, he believed that the average age of successful entrepreneurs is 40 years, and most entrepreneurs are University graduates. [20] But more scholars focus on the study of random effects variables. Second, variable architecture system. In the related research on the technology architecture of the technology incubation platform, the following scholars' views are worthy of attention. Chaffik (2013) defined the key indicators of the effective operation of the incubator system in two levels. The first level includes 6 indicators, they are achievement, cultivation, financial resources, networking, technology, and management. The second level includes 21 indicators, they are the number of incubation projects, project delivery rate, job creation rate, survival rate, full incubation rate, Intention, enterprise selectivity, financial resources, economic and trade partners, low cost, stakeholder resources, professional networks, systems, participation, tool provision, service, management quality, information system, experience exchange, mentor experience, training and key skills. [21] Li Chengguang and Zhang Yongan (2013) proposed a research framework that takes subsidies, tax benefits, talents, resources and laboratories as independent variables and innovation efficiency as dependent variables to measure the impact of regional innovation policies on innovation efficiency. [22] Sang (2004) proposed a two-level system, first-level includes 4 indicators, they are target and operation strategy, entity and human resources situation, service situation and network support; two-level includes 14 indicators, they are challenge and clarity of objectives, specificity and feasibility of business strategies, convenient access facilities and equipment, convenient service space and office equipment, entrepreneurship support network, expert resources, technology transfer, technology research and development (R\&D), commercial legal consultation, financial support and consultation, entrepreneurship education plan, machine. Network construction, business incubation, and graduation network, financing advisory network, and support of government and local community. [23] Tension (2016) established the structural system of the dependent variables-control variables-interpreted variable, in which the selection of dependent variables are " 0 " and " 1 ", " 0 " represents failure, "1" represents successful graduation; The control variables are the internal causes, including the entrepreneur's education background, age, gender, and the enterprise's industry attribute; explanatory variables are divided into two categories, one is the factor derived from the entrepreneur, that is, the entrepreneurial experience; the other is the factors derived from the incubator, including the experience of the incubator managers, Incubation funds and web interfaces. [24] Huang Hong (2013) set the structural system as two categories: input indicators and output indicators. The input indicators include incubator staff, incubation fund, the cumulative number of graduated enterprises, site area and total income. The output indicators are the number of incubating enterprises, the number of incubators and the income level. [25] Third, the study of dependent variables. In addition to the related research by
Huang Hong (2013), Li Chenguang, Zhang Yongan (2013) and others in order to measure the effectiveness of the incubator, Handi (2011) proposed four performance measures, they are the graduation rate, success rate, number of jobs and wage. [26] Michael (2011) used employment numbers and sales as performance indicators. [27] Teresa (2015) and others used the service quality of incubators as a measure. [28] Wu Wenqing (2018) and others used incubator profits as performance indicators. [29] The above scholars have studied the failure effects independent variables, variable structures and dependent variables, and this paper believes that the existing results have the following defects: First, there are many repetitive variables and key variables are not prominent, there are many repetitions in the selection of random influence variables. For example, most scholars are aware of the importance of networks and institutions, but few scholars have listed this most important variable as the first variable to study. This article explicitly lists the "network and institution" variables as the first variable. Second, the number of variables is incomplete or can't be quantified. The number of variables selected by the above scholars varies from one to 21 . Chaffik (2013) listed 21 indicators, which are the most operable indicators system, but the fatal defect is that some indicators can only be scored and cannot be quantified, so that the variable indicators cannot be accurately quantified due to subjectivity.

In selecting indicators, this paper follows two principles: variable indicators should be complete, there will be loopholes if the indicators are not complete; variables should be quantifiable, and indicators that can't be quantified are not included in the statistical system. Based on this, this paper selected 18 variables as independent variables of random influence according to the characteristics of the background of the big data, they are name of incubation platform, network and organization, area, number of management, type of service, number of activities, service input, investment in self-established fund, main body of operation, number of companies in custody, investment in $R \& D$, number of employees, number of financing companies, total financing, government support, time, corporate activities and corporate self-owned funds. In the background of big data, most of these variables are random, that is, the value of each technology incubation platform is random and uncertain. For the design of the variable architecture system, according to the literature research, this paper believes that Huang Hong (2013) divided the variables into input and output variables, which is the most consistent with the complexity and dynamic characteristics of the technology incubation platform. This paper does not agree to divide the indicator system into the first-level indicator and the second-level indicator system. In the background of big data and new scenarios, the randomness of variables is more obvious, every variable is equal, the traditional hierarchical variables are not applicable here. According to the current trend of mainstream research, the most advanced research methods are based on random variables. The research results will be extremely unstable if the influence of random variables is not considered. For dependent variables, this paper argues 
that dependent variables should reflect multi-dimensionality, and can not only take one dependent variable, which is determined by the randomness and complexity of the technology incubation platform. This paper determines the following four variables as dependent variables, they are incubator income, total enterprise income, number of graduated enterprises and number of intellectual property rights.

The random perturbation term brought about by the new technological revolution is $\varepsilon$, which consists of two kinds of random variables: one is the random variable generated by the technology incubation platform, which is called X series for short, it is composed of random parameters such as network and institution, activity number, service input, self-established fund input; the other is simple and generated by the start-up enterprise itself, called $\mathrm{Z}$ series, it is composed of random parameters, such as the number of incubating enterprises, investment of $R \& D$, employment, financing enterprises, total financing, government support and so on. $\mathrm{X}$ is an external variable for start-ups and is not controlled by start-ups; $\mathrm{Z}$ is a self-variant of start-ups and can be controlled by start-ups. The parametric random variables embody the characteristics of the randomly affected variables, the model should be calculated by SAF, which is the mathematical method that reflects the parametric random variables.

The variable table in this paper is shown in Table 2. Among them: $Y_{i}$ represents the dependent variables, that is, the measured value of the failure effects; $X_{i}$ and $Z_{i}$ represent the random influence of the independent variables. $Y_{i}=$ $\left\{Y_{1}, Y_{2}, Y_{3}, Y_{4}\right\} ; X_{i}=\left\{X_{1}, X_{2}, X_{3}, X_{4}, X_{5}, X_{6}, X_{7}, X_{8}, X_{9}\right\} ; Z_{i}=$ $\left\{Z_{1}, Z_{2}, Z_{3}, Z_{4}, Z_{5}, Z_{6}, Z_{7}, Z_{8}, Z_{9}\right\}$

Table 2. Variables Settings Table.

\begin{tabular}{|c|c|c|c|c|}
\hline Variables & Value & Name & Unit & Variables description \\
\hline $\mathrm{X}_{1}$ & & Name of incubation platform & & \\
\hline $\mathrm{X}_{2}$ & $\operatorname{lnNet}$ & Networks and institutions & & Providing funds and talent input \\
\hline $\mathrm{X}_{3}$ & $\operatorname{lnSqu}$ & Area & Square meter & Area of office space \\
\hline $\mathrm{X}_{4}$ & $\ln$ Man & Number of managed persons & & Platform staff \\
\hline $\mathrm{X}_{5}$ & $\operatorname{lnSer}$ & Type of service & & Types of Platform Services \\
\hline $\mathrm{X}_{6}$ & $\ln A c t$ & Number of activities & & Activities organized by platform \\
\hline $\mathrm{X}_{7}$ & $\operatorname{lnSIn}$ & Service input & Ten thousand yuan & Annual input of Platform Service \\
\hline $\mathrm{X}_{8}$ & $\operatorname{lnFun}$ & Input of self-established fund & Ten thousand yuan & Annual input of platform self-established fund \\
\hline $\mathrm{X}_{9}$ & Reference & Main body of operation & $1,2,3$ & $\begin{array}{l}1=\text { State-owned property } ; 2=\text { Private property } ; 3= \\
\text { University }\end{array}$ \\
\hline$Z_{1}$ & $\operatorname{lnCom}$ & Number of incubating enterprises & & \\
\hline $\mathrm{Z}_{2}$ & $\ln \mathrm{RD}$ & Input of R\&D & Ten thousand yuan & Start-ups' input of R\&D \\
\hline $\mathrm{Z}_{3}$ & $\ln$ Wor & Number of employed persons & & Employees of start-ups \\
\hline $\mathrm{Z}_{4}$ & $\operatorname{lnFCo}$ & Number of financing enterprises & & \\
\hline$Z_{5}$ & $\operatorname{lnFSu}$ & Total financing & Ten thousand yuan & \\
\hline $\mathrm{Z}_{6}$ & $\operatorname{lnGov}$ & Governmental support & Ten thousand yuan & Government-funded amount \\
\hline$Z_{7}$ & $\operatorname{lnTim}$ & Time & Year & \\
\hline$Z_{8}$ & Reference & Enterprise activity & & \\
\hline$Z_{9}$ & Reference & Enterprise owned fund & Ten thousand yuan & \\
\hline $\mathrm{Y}_{1}$ & $\operatorname{lnIOu}$ & Incubator income & Ten thousand yuan & \\
\hline $\mathrm{Y}_{2}$ & $\operatorname{lnCOu}$ & Total enterprise income & Ten thousand yuan & \\
\hline $\mathrm{Y}_{3}$ & $\operatorname{lnSuc}$ & Number of graduated enterprises & & \\
\hline$Y_{4}$ & lnKno & Number of intellectual property rights & & \\
\hline
\end{tabular}

\section{Empirical Research}

\subsection{Data Sampling, Correlation Analysis, Reliability Testing, Data and Research Hypothesis}

This paper selects the region with the most developed background of Chinese big data----Beijing as a sampling area, Beijing has a total of more than 400 business incubators, university incubators, and maker space. According to the accessibility of the address, a total of these platforms are targeted. A total of 339 questionnaires were distributed and rejected, and 29 samples with invalid samples or obvious contradictions were excluded. The valid samples collected were 310 samples for analysis. Through the correlation analysis between variables, there is a clear correlation between $\mathrm{Z}_{8}$ corporate activities and the number of $\mathrm{X}_{6}$ activities. This is because the number of activities held by the technology incubator and the number of corporate activities is repeated; $Z_{9}$ corporate free cash (distributable cash) has a significant correlation with $Z_{2} R \& D$ investment, this is because the company's $R \& D$ investment generally accounts for a certain proportion of the company's free cash, and the two have cross-cutting. This paper will delete the $Z_{8}$ corporate activities and $Z_{9}$ enterprise free cash, the remaining 18 variables are independent variables, where $X_{1}$ is the name variable and $\mathrm{X}_{9}$ is the ordered variable. Both are no longer used for formula analysis because they cannot be measured. They are only used as reference variables to get a definition and correlation table for the identified variables, as shown in Table 2. The names corresponding to the variables are as follows: name--hatchery name, lnNet--number of networks and institutions, lnSqu--area, lnMan--number of managed persons, lnSer--type of service, lnAct--number of activities, lnSIn--service input, $\operatorname{lnFun--self-established~fund,~}$ $\operatorname{lnCom}$ - number of incubating enterprises, $\operatorname{lnRD}$ - input of 
R\&D, lnWor-numbers employed persons, lnFCo--number of financing, lnFSu--total financing, lnGov--governmental support, lnTim--time, lnIOu--incubator income, lnCOu--total enterprises income, lnSuc--number of graduated enterprises, lnKno--number of intellectual property rights. In addition, the operating entity is an ordered variable and is not used for empirical analysis. Then, the reliability statistics of the remaining 14 independent variables and 4 dependent variables are obtained, the cloned Bach coefficient and the cloned Bach coefficient based on the standardized project reach 0.945 and 0.939 respectively, which have high reliability and can be used for subsequent operations.

This paper proposes the following general assumptions: assume that the dependent variable combination $Y_{1 \sim 4}$ correlates with the independent variable combination $\mathrm{X}_{2 \sim 8}$ and
$Z_{1 \sim 7}$. For the empirical analysis, take the corresponding variable as the $\ln$ value. According to Table 2, make the following assumptions: it is assumed that $\ln \mathrm{IOu}, \operatorname{lnCOu}, \operatorname{lnSuc}$, and $\operatorname{lnK}$ no are related to $\operatorname{lnNet}, \ln \mathrm{Squ}, \ln \mathrm{Man}, \operatorname{lnSer}$, $\ln$ Act, $\operatorname{lnSIn}, \operatorname{lnFun}$, lnCom, lnRD, lnWor, $\operatorname{lnFCo}, \operatorname{lnFSu}$, lnGov, and $\operatorname{lnTim}$, respectively. If the assumption is rejected, it indicates that the variable is independent of the corresponding dependent variable.

\subsection{Empirical Analysis}

Substituting data into Stata software for analysis, the result output table of the randomly affected variable after iteration, as shown in Table 3.

Table 3. Result output table.

\begin{tabular}{|c|c|c|c|c|c|c|c|c|}
\hline \multirow{2}{*}{ InIOu } & \multicolumn{2}{|l|}{$Y_{1}$} & \multicolumn{2}{|l|}{$Y_{2}$} & \multicolumn{2}{|l|}{$\mathbf{Y}_{3}$} & \multicolumn{2}{|l|}{$\mathbf{Y}_{4}$} \\
\hline & Coef. & $\mathbf{P}>|\mathbf{z}|$ & Coef. & $\mathbf{P}>|\mathbf{z}|$ & Coef. & $\mathbf{P}>|\mathbf{z}|$ & Coef. & $\mathbf{P}>|\mathbf{z}|$ \\
\hline $\operatorname{lnNet}$ & .32 & 0.00 & .34 & 0.00 & -.09 & 0.06 & .00 & 0.90 \\
\hline $\operatorname{lnSqu}$ & .48 & 0.00 & .10 & 0.01 & -.004 & 0.93 & .28 & 0.00 \\
\hline $\operatorname{lnMan}$ & .09 & 0.17 & .04 & 0.22 & .24 & 0.00 & -.00 & 0.97 \\
\hline $\operatorname{lnSer}$ & .02 & 0.74 & -.13 & 0.00 & .06 & 0.27 & -.18 & 0.00 \\
\hline $\ln A c t$ & .32 & 0.00 & .30 & 0.00 & .06 & 0.37 & .09 & 0.28 \\
\hline $\operatorname{lnS} \operatorname{Sn}$ & .40 & 0.00 & .05 & 0.01 & -.01 & 0.60 & .09 & 0.00 \\
\hline $\operatorname{lnCom}$ & .15 & 0.17 & -.13 & 0.02 & .79 & 0.00 & .57 & 0.00 \\
\hline $\ln R D$ & .08 & 0.02 & .11 & 0.00 & .03 & 0.09 & .04 & 0.16 \\
\hline $\ln$ Wor & .13 & 0.23 & .74 & 0.00 & -.40 & 0.00 & -.15 & 0.07 \\
\hline $\operatorname{lnFCo}$ & .31 & 0.00 & .17 & 0.00 & .22 & 0.00 & .11 & 0.09 \\
\hline $\operatorname{lnFSu}$ & -.14 & 0.00 & -.04 & 0.00 & .03 & 0.07 & .11 & 0.00 \\
\hline $\operatorname{lnGov}$ & .16 & 0.00 & -.001 & 0.95 & .03 & 0.24 & .24 & 0.00 \\
\hline $\ln$ Tim & -.79 & 0.00 & .25 & 0.00 & .46 & 0.00 & .33 & 0.00 \\
\hline Lambda & .01 & & .01 & & 2.44 & & 2.23 & \\
\hline
\end{tabular}

First, the performance of the technology incubator platform $\operatorname{lnIOu}$ and $\operatorname{lnNet}$, $\operatorname{lnSqu}, \ln A c t, \operatorname{lnSIn}, \ln \mathrm{RD}, \operatorname{lnFCo}$, $\operatorname{lnFSu}, \operatorname{lnGov}, \operatorname{lnTim}$ significant, however, the relationship with lnMan, $\operatorname{lnSer}$, lnFun, $\operatorname{lnCom}$, lnWor is not significant. The assumptions concerning this part of the variable do not hold. Substituting the coefficients with correlation variables into formula (3):

$\operatorname{lnIOu}=-2.72+0.32 \ln N e t+0.48 \ln S q u+0.32 \ln A c t+$ $0.40 \ln S \ln +0.08 \ln R D+0.31 \ln F C o-0.14 \ln F S u+0.16 \ln$ Gov -

$$
0.79 \ln \text { Tim }-\mathrm{u}_{1}+\mathrm{v}_{1}
$$

As can be seen from equation (7) and table $3, \lambda=$ $\frac{\delta_{\mathrm{u} 1}}{\delta_{\mathrm{v} 1}}=0.0136 . \mathrm{u}_{1}$ represents the ineffective failure effects, because the value of $\lambda$ is small, it can be very small, indicating that the failure effects are not obvious in the perspective of the performance of the technology incubator, mainly reflected in the effective effects. $v_{1}$ stands for random error term. The large value of $v_{1}$ indicates that the loss rate of the performance of the technology incubator mainly comes from the random error term, that is, mainly from the external changes. In the context of the "Big data", the external environment has further increased the uncertainty of the system, but in general, the "Big data" has increased the chances of human-to-human interaction, human-to-machine interaction and human-to-platform interaction compared with traditional communication channels. These "good" can further amplify the effective effects and promote the increase in income from the technology incubator platform.

Second, the total income of the start-ups $\operatorname{lnCOu}$ is significantly related to $\operatorname{lnNet}, \operatorname{lnSqu}, \operatorname{lnSer}, \ln A c t, \operatorname{lnSIn}$, $\operatorname{lnCom}, \operatorname{lnRD}, \operatorname{lnFCo}, \operatorname{lnFSu}, \ln$ Tim, this part of the variable is not rejected, but the relationship with lnMan, $\operatorname{lnFun}, \operatorname{lnGov}$ is not significant. Organize the coefficients of the significant variables:

$\operatorname{lnCOu}=2.22+0.34 \ln N e t+0.10 \ln S q u-0.13 \ln$ Ser $+0.30 \ln A c t+$ $0.05 \ln S \operatorname{In}-0,13 \ln$ Com $+0.11 \operatorname{lnRD}+0.741 \ln W o r+0.17 \ln F C o-$

$$
0.04 \ln F S u+0.25 \ln T i m-u_{2}+v_{2}
$$

$\lambda=\frac{\delta_{\mathrm{u} 2}}{\delta_{\mathrm{v} 2}}=0.0101$. The $\mathrm{u}_{2}$ value is small, indicating that the failure effects from the perspective of the total income of the start-ups are not obvious, and it shows an effective effect.

$\mathrm{v}_{2}$ represents a random error term. The larger value of $\mathrm{v}_{2}$ indicates that the loss rate of the total revenue of the startup is mainly from the random error term. Under the background of the "Big data", start-ups have been favored by the capital market, and at the same time, new financing and outsourcing projects such as crowdfunding and 
crowdsourcing have been added. These factors have increased the effective effect and promoted an increase in the total income of start-ups. At the same time, new business models emerged in the context of the "Big data", and their uncertain risks increased, which also brought the volatility of the total income of start-ups.

The third is the random influence variable of the number of graduated companies lnSuc, Sorting the coefficients of the variables that are not rejected:

$$
\operatorname{lnSuc}=-1.24+0.24 \operatorname{lnMan}+0.03 \ln \text { Fun }+0.79 \ln \text { Com }-
$$$$
0.40 \ln W o r+0.22 \operatorname{lnFCo}+0.46 \ln \mathrm{Tim}-\mathrm{u}_{3}+\mathrm{v}_{3}(9)
$$

$\lambda=\frac{\delta_{\mathrm{u} 3}}{\delta_{\mathrm{v} 3}}=2.44$. The large value of $\mathrm{u}_{3}$ indicates that the failure effects are obvious from the perspective of the number of graduated enterprises. From equation (9), it can be seen that the number of graduated companies $\operatorname{lnSuc}$ is significantly related to $\operatorname{lnMan}, \operatorname{lnFun}, \operatorname{lnCom}$, lnWor, $\operatorname{lnFCo}$, and $\operatorname{lnTim}$. The failure effects are mainly caused by the number of management of the technology incubation platform, the number of self-established funds, the number of employees in the incubation, the number of employees employed, the number of financing enterprises and time.

Fourth, random impact variables of intellectual property number perspective (lnKno), organize variables that are not rejected in the hypothesis:

$\ln$ Kno $=-3.02+0.28 \operatorname{lnSqu}-0.18 \ln S e r+0.09 \ln \operatorname{SIn}-$ $0.04 \ln$ Fun + 0.57lnCom + 0.11lnFSu + 0.24lnGov +

$$
0.33 \ln \text { Tim }-u_{4}+v_{4}
$$

$\lambda=\frac{\delta_{\mathrm{u} 4}}{\delta_{\mathrm{v} 4}}=2.23$. It can be seen that the value of $\mathrm{u}_{4}$ is large, indicating that the failure effects are obvious from the perspective of intellectual property. From equation (10), it can be seen that the number of intellectual property rights lnKno is significant. The failure effects are mainly caused by the area of the technology incubation platform, the type of service, the service investment, the self-established fund, the number of companies in the incubation, the number of financing companies, government support, and time.

\subsection{Definition of Failure Effects Variables}

The empirical study results are compiled to obtain random failure effects variables map, as shown in Figure 1. The random variables of the failure effects that are not rejected by empirical tests are divided into three categories. One is the positive correlation variable, including $\operatorname{lnNet}$, $\operatorname{lnSqu}$, lnMan, lnAct, $\operatorname{lnSIn}, \ln R D, \operatorname{lnFCo}, \operatorname{lnGov}$, the larger the value, the better the output, and the less obvious the failure effects. Second, negative correlation variables, including $\operatorname{lnSer}$, which represents the type of service of the technology incubator itself. The increase in the number of services has brought about a decline in the total revenue and intellectual property rights of start-ups. This indicates that under the current background of the "Big data", the technology incubation platform should provide the appropriate and accurate services as the best choice. Good services that do not perform optimally should be delegated to external partner agencies. The third is a local unrelated variable. Including lnFun, $\operatorname{lnCom}$, lnWor, $\operatorname{lnFSu}$, lnTim, their relationship with the four dependent variables is irrelevant, some related, especially referred to as local unrelated variables. InFun represents a self-established fund. The increase in self-established funds will help the number of graduated enterprise, but it is not good for intellectual property rights. This is because self-owned funds are mostly used for equity investment in start-ups, thus the input and output of intellectual property rights of start-ups are constrained, and the desperate investment in $R \& D$ is reduced, but it also affects the output of intellectual property. lnCom represents the number of incubating enterprises. The increase in the number of incubating enterprises is conducive to the number of graduated enterprises and the number of intellectual property rights. However, the carrying capacity of the technology incubator platform has the best scale limitation. Too many incubating enterprises will affect the hatching effect of the incubating enterprises, leading to a reduction in total revenue of start-ups. InWor represents the number of employed people, the increase in employment will increase the total income of start-ups. At the same time, it will bring about an increase in costs or cause people to be overstaffed, resulting in a decline in efficiency and a decline in the number of graduates. $\operatorname{lnFSu}$ represents the total financing of start-ups, the total amount of financing increases, and the number of knowledge output increases. However, in the context of the new technological revolution, enterprises burn money. Once they get financing, in order to obtain refinancing, they must maintain a very high growth rate. At the touch of a button, the income of the technology incubator platform and the total income of the start-ups will not rise and fall after reaching a certain scale. InTim stands for time variable, the birth time of technology incubator is prolonged or the incubation time of incubating enterprises is prolonged. The accumulation of management experience will stimulate the total income of start-up enterprises, the number of successful graduates, and the increase of intellectual property rights. However, the technology incubation platform itself is prone to management rigidity. It is no longer adapted to the new situation of the "Big data", which has led to a corresponding decrease in new companies, which has led to a decline in overall efficiency and a decline in the income of the technology incubator platform.

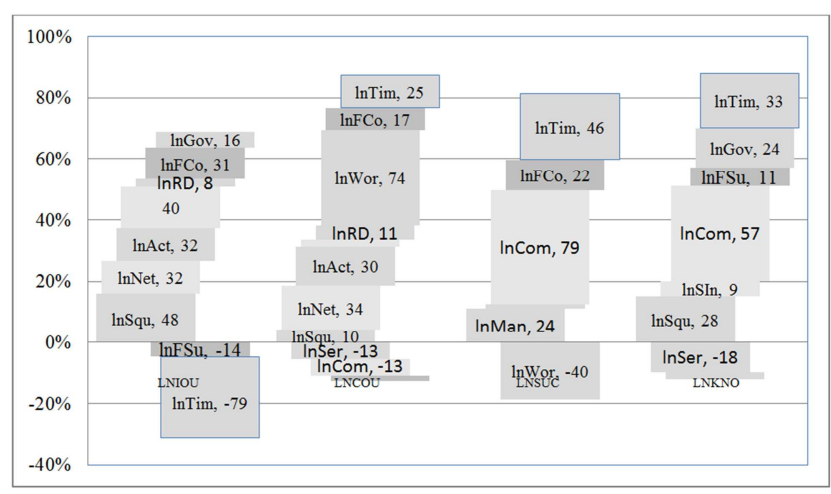

Figure 1. Definition of failure effects variables. 


\section{Main Research Conclusions}

First, the new technological revolutionary background increases the disturbance variables of the technology incubation platform, and each dependent variable corresponds to a different negative correlation variable or irrelevant variable. According to empirical research, in the current environment of the new technological revolution, for the income of the technology incubator platform, the management number $\operatorname{lnMan}$, the service type $\operatorname{lnSer}$, the self-set fund investment $\ln F$ un, the number of incubating companies $\operatorname{lnCom}$, the employment number $\ln$ Wor are irrelevant variables, financing The total amount $\operatorname{lnFSu}$ and the time $\operatorname{lnTim}$ are negative correlation variables. For the total income of start-ups, the management number lnMan, the self-set fund investment lnFun, the government support lnGov are irrelevant variables, the service type $\operatorname{lnSer}$, the number of incubation companies lnCom, and the total financing amount $\operatorname{lnFSu}$ are negative correlation variables. For the number of graduated enterprises, network and organization $\operatorname{lnNet}$, area $\operatorname{lnSqu}$, service type $\operatorname{lnSer}$, activity number $\ln A c t$, service investment $\ln S I n, R \& D$ investment $\operatorname{lnRD}$, total financing $\operatorname{lnFSu}$, government support lnGov are irrelevant variables, employment number lnWor is a negative correlation variable. For the number of intellectual property rights, network and organization lnNet, management number lnMan, activity number lnAct, R\&D investment $\ln R D$, employment number lnWor, financing enterprise number lnFCo are irrelevant variables, service type lnSer, self-designed fund investment $\operatorname{lnFun}$ is a negative correlation variable. Similar to the viewpoint of Zhang li (2016), this paper believes that with the extension of time, the technology incubation platform will become rigid and unable to adapt to the new form. According to Zhang li's research, enterprises that fail to graduate within 930 days are less likely to graduate later. Compared with the research of Huang Hong (2013) and Li Chenguang (2014), this paper further explores the impact of government support on the technology incubation platform. Huang Hong believes that policy support can have a significant positive effect on the operation of technology business incubators. Li Chenguang believes that government support has a great influence on the number of patents of the incubation platform and other aspects. This paper also believes that government support has a great influence on the technology incubation platform, but it is unrelated to the total income of the start-up enterprises and the number of enterprise graduates.

Second, when a negative correlation variable or a local irrelevant variable acts on the corresponding dependent variable, a failure phenomenon will occur, and the technology incubator platform exhibits a failure effects characteristic. It can be seen that the failure phenomenon of the technology incubator platform exists objectively, but because different random influence variables have different effects on different dependent variables, it leads to various rational phenomena, which is the root cause of major academic disputes. In this paper, the series of failure effects derived based on the failure effects of 14 quantifiable independent variables on four dependent variables show that the effects of different random influence variables on the dependent variables are different, which is the root cause of each rationality. The empirical conclusions of this paper provide a more comprehensive and reasonable explanation for current academic disputes.

Third, the failure effects coefficient $\lambda$ value represents the overall failure level of the technology incubation platform. The higher the failure effects coefficient $\lambda$ value, the greater the failure effects of the technology incubation platform, and the greater the loss caused by the random disturbance variable.

In summary, this paper focuses on the partial failure of the technology incubator platform that has received much attention in the context of the new technological revolution. Starting from the combing and definition of the complex variables of random disturbance factors, the mechanism of failure effects is studied by using the principle of stochastic frontier model, the concept of failure effects and coefficient is proposed, and the failure effects mechanism formula is derived, an empirical study was conducted, a new explanation for the local failure phenomenon of the current technology incubator platform is provided.

\section{Acknowledgements}

This paper is the result of the Beijing Municipal Social Science Fund Key Project "Study on the Incentive, Conduction and Diffusion Mechanism of Beijing Maker Space Innovation Power Source". (17GLA007)

\section{References}

[1] Ferguson R \& Olofsson C. Science parks and the development of NTBFs. Location, survival and growth [J]. Journal of Technology Transfer, 2004, 29 (1): 5-17.

[2] Sutherland D. China's science parks: production bases or a tool for institutional reform? [J]. Asia Pacific Business Review, 2005, 11 (1): 83-104.

[3] Harwit E. High-technology incubators: fuel for China's new entrepreneurship? [J]. The China Business Review, 2002, 29 (4): 26-29.

[4] Tamasy C. Rethinking technology-oriented business incubators: developing a robust policy instrument for entrepreneurship, innovation, and regional development? [J]. Growth and Change, 2007, 38 (3): 460-473.

[5] Salador E, Rolfo S. Are incubators and science parks effective for research spin-offs? Evidence from Italy [J]. Science and Public Policy, 2011, 4: 170-184.

[6] Tondolo L P, BEL. Business incubators: many public investments, much noise, and the results? [J]. Journal of Management and Planning. Salvador, 2016, 17 (2): 298-313.

[7] Develear E J, Nijkamp P. The incubator hypothesis: revitalization of metropolitan areas? [J]. Annals of Regional Science, 1988, 22 (3): 48-56. 
[8] Dutt N, Hawn O, Vidal M, Chatterji A, Mcgahan A. How open system intermediaries address institutional failures: the case of business incubators in emerging-market countries [J]. Academy of Management Journal, 2015, 59 (3): 818-840.

[9] Zhu Xiumei. Empirical Research on Innovation Path and Mechanism of High-tech Industry Clusters [J]. Chinese Industrial Economy, 2008 (10): 42-48. (in Chinese)

[10] Rice M P. Co-production of business assistance in business incubators- -An exploratory study [J]. Journal of Business Venturing, 2002 (17): 163-187.

[11] Aiger, Lovell, Schmidt, Meeusen. Formulation and estimation of stochastic frontier production function models [J]. Journal of Econometrics, 1977 (6): 21-37.

[12] Smilor RW. Managing the incubator system: critical success factors to accelerate new company development [J]. IEEE Transactions on Engineering Management, 1987, 34 (3): 146155.

[13] Park G, Shin K, Han ST. A Study on the present conditions of technology business incubator and its efficient operation [J]. The Korean Small Business Review, 1999, 21 (2): 111-138.

[14] Lee JJ, Kim JS, Chun H K. A Study on the management and financial independence of university technology business incubators (UTBIs) in information and telecommunication industry [J]. Korean Small Business Review, 1999, 21 (2): 185-206.

[15] Hansen MT, Chesbrough HW, Sull DN. Networked incubators: houses of the new economy [J]. Harvard Business Review, 2000, 78 (5): 74-84.

[16] Pace G. Incubators as catalysts of academic spin-offs: evidence from the Israeli case-study [R]. The 42nd European Regional Science Association Congress, held 27-31 August 2002, Dortmund, Germany.

[17] Colombo MG, Delmastro M. How effective are technology incubators? Evidence from Italy [J]. Research Policy, 2002, 31 (7): 1103-1122.

[18] Link A N, Scott J T. The economics of university research parks [J]. Oxford Review of Economic Policy, 2007, 23 (4): 661-674.

[19] Schwartz M. Beyond incubation: an analysis of firm survival and exit dynamics in the post-graduation period [J]. Journal of Technology Transfer, 2009, 34 (4): 403-421.

[20] Mian SA. U.S. University ponsored technology incubator: an overview of management, policies, and performance $[\mathrm{J}]$. Technovation, 1994, 14 (8): 515-529.

[21] Bakkali C. For a tool for measuring and controlling the performance of incubators [J]. Management International, 2013, 17 (3): 140-152.

[22] Li Chenguang, Zhang Yongan. An Empirical Study on the Impact of Regional Innovation Policy on Enterprise Innovation Efficiency [J]. Scientific Research Management, 2014, 5 (9): 25-34. (in Chinese)

[23] Lee S S, Jerome S, Osteryoung. A comparison of critical success factors for effective operations of university business incubators in the United States and Korea [J]. Journal of Small Business Management, 2004, 42 (4): 418-426.

[24] Zhang Li, Zhou Yongtao, Qi Ruqing. Analysis of incubator performance based on panel data of incubating enterprises [J]. Soft Science, 2016, 30 (11): 5-9 (in Chinese)

[25] Huang Hong, $\mathrm{Xu}$ Yuehui. Research on Operational Performance and Regional Differences of Chinese Technology Business Incubators [J]. Exploring Economic Issues, 2013 (7): 144-151 (in Chinese)

[26] AL-Mubaraki H, Holgoer. Measuring the effectiveness of business incubators: A four dimensions approach from a gulf cooperation council perspective [J]. Journal of Enterprising Culture, 2011, 19 (4): 435-452.

[27] Schwatrz M. Incubating an illusion? Long-term incubator firm performance after graduation [J]. Growth and Change, 2011, 42 (4): 491-516.

[28] Femandeza M, Francisco J, Jimeneza B, Juan R, Roura C. Business incubation: innovative services in an entrepreneurship ecosystem [J]. The Service Industries Journal, 2015, 35 (14): 783-800.

[29] Wu Wenqing, Yu Kexin, Liu Wenyi, Li Chaoqun. Research on Technology Business Incubator and Venture Capital Cooperation under Fair Preference [J]. Journal of Tianjin University (Social Science Edition), 2018 (2): 116-120. (in Chinese) 